\title{
THE REGULATORY MODEL OF ENERGY SERVICES’ GOVERNANCE IN THE EU
}

\author{
Lyubimka Markova Andreeva \\ Dr., Chief Assistant Professor at Sofia University "St. Kliment Ohridski”, \\ Department of Public Administration. \\ Address: 15 Tsar Osvoboditel Blvd., 1504 Sofia, Bulgaria. \\ E-mail: lubima.andreeva@abv.bg
}

\begin{abstract}
Over the past few decades there has been a significant change in the way we view the development processes of energy services governance in the European Union (EU) and on a national level. The latest analysis has shown that, after the processes of liberalization and deregulation, the former exceptions to the rules of competition in Europe begin to assume different corporate forms, instead of the purely public enterprise, making a shift in the direction of the regulated mixed-economy. From this point of view, the aim of the article is to present an overview of the new public governance approach to delivering electricity services in the EU (the regulatory state) and the effect of it, particularly in the Bulgarian energy sector - the electricity market. The European regulatory model of energy services is a relatively new approach which appeared in the last two decades of the 20th century and it is part of the wider debate about the liberalization of electricity services in the EU. It is going to be used alongside a combination of approaches including institutional, normative and expert analysis in order to better understand the model of regulations in the EU. The results of the paper could help both theoreticians and practitioners to note the fact that the paradigm of supplying energy services nowadays has changed. This leads to different challenges in contemporary public governance as well as on a national level, in which the main goals are to protect the public interest on the one hand, and to facilitate competition on the other.
\end{abstract}

Keywords: European Union; Regulations; Governance; Energy Services; Services of General Interest.

Citation: Andreeva, L.M. (2018). The Regulatory Model of Energy Services' Governance in the EU. Public Administration Issues, Special Issue (electronic edition), pp. 21-42 (in English); DOI: 10.17323/1999-5431-2018-0-5-21-42.

\section{Introduction}

The governance of public services in Europe underwent significant changes during the last two decades of the twentieth century. Public services, such as energy services, and the relative processes of privatization, liberalization, deregulation or nationalization have been a subject of intense debate among po- 
litical leaders from the public governance area, economists and practitioners in Europe for many years. Therefore, ideas on how to manage public utilities have often changed and practical solutions chosen for it have also undergone significant changes over time. Nowadays, we are witnessing a renewed debate on the appropriate option for governance of the provision of public services in Europe. Privatization and liberalization processes have begun to dominate. Furthermore, in the European Union we see "the creation of internal market facing a new paradigm change that will lead to a future power system that is very different from the present one. Intense political oversight and intervention are already taking place in the form of all sorts of new energy policies, and much more is anticipated. In the future, the criteria of security and sustainability will have at least the same priority as efficiency in the regulatory design" (Pérez-Arriaga, 2013). This makes "European integration an ideal issue to study the framing strategies of political actors and to the sphere of economic affairs" (Hoeglinger, 2016). In this regard, the purpose of the article is to clarify the newest aspect of energy services governance and its challenges in the European Union in the $21^{\text {st }}$ century, the emergence of the so-called Regulatory state, and how much can be discussed about the effective regulation of these services at national level, as a consequence of this change. The reason for pointing out these questions is not accidental. From a historical point of view, managing public utilities has only ever been subjected to one of the two power regulators - the State or the Market. This model is characterized by the fact that it gives priority either to State or Market regulation, often relying only on one of them to produce an overall effect of governance. In Europe, the provision of public goods and services has been predominantly the traditional mode of economic regulation over time. However, subsequent experience has demonstrated that the public provision doesn't provide the overall effect for its implementation. The reasons for this are obvious - "the nationalized enterprises combine the worst of two worlds - the lack of a long-term strategy on the provision of public goods and services and constant government intervention in their activities. In this regard, the idea of imposing effective governance control over nationalized enterprises proved so intractable that the main objective for which they had been allegedly created - the regulation of the economy in the public interest - was almost forgotten" (Majone, 2010). Indeed, it should be noted that at European level, the nationalization failed not only as a mode of economic regulation, but also with respect to the socio-political objectives of consumer protection. The same can be said about the functioning of the market. According to liberal ideas, the market is usually considered as the perfect regulator of the exchange of goods and services. This is also the policy of neoliberalism of the 1980s, which suggests that the market itself can meet the needs of society even when its weaknesses need to be "repaired". However, some public services, such as energy services (or services of general interest - SGI, as they are known in Europe) cannot be subject only to market allocation mechanisms because the market price is too high for consumers with low purchasing power or because the cost of providing these services could not be covered by the market price. A majority of economists in this period "recognized that the sector of public utilities presented some sort of market 
failure (even though this precise term was not used for a long time) and therefore had to be somehow supervised by public hand. This did not imply that public enterprise should be chosen over private enterprise. Two main arguments, typical of the then liberal position, were raised against public enterprise: on the one hand, there were doubts on the opportunity to expand the role of the state, seen as limiting the space of individual autonomy: on the other hand, there was some sort of scepticism on the ability of a public enterprise to be efficient, being too prone to bureaucratic behaviour" (Bognetti, 2008). This total reformulation of priorities has led to a change in thinking and understanding of policies and governance of services of general interest nowadays. The traditional approach based on the State supply of services has been replaced by the new one - the Regulatory State. This happened during the latter two decades of the last century, when the traditional "natural" State monopolies, such as the energy sector, began to assume different corporate forms, instead of the purely public enterprise. It should be noted, however, that the change in the concept of governance in the delivery of public services does not imply that the State disappears completely and is replaced by the rules of the Market, but only that it changes its role. Today, public authorities are beginning to delegate their responsibility to the private sector. Governmental authorities limit their own roles regarding regulation, including defining public goals, monitoring, and when it is necessary financing services. The State has become one of the many political partners, its place and role depending solely on the power resources inherent within it. The political power itself from a vertical relationship becomes a horizontal, depending on different partner's' interest. So, what has changed now is the way in which public authorities fulfill their responsibility to society. As Majone said, what preceded the contemporary EU state is not some pure laissez faire regime but another regulatory state. Regulations are an instrument of European policy which aim to control the release of goods and services on the market with an emphasis on consumer rights. Even more, "now it is the new dimension to regulation-both in the content and role of the regulatory institutions-that must accompany the revolutionary challenge expected of power systems around the world in the next few decades to contribute to the transition to a sustainable energy model" (Pérez-Arriaga, 2013). This new dimension leads to different challenges in contemporary public governance in order to better understand the content and the role of the Regulatory state in the future. What is new now "is not only a question of markets versus governments. It is also not only the still open issues in the usual topics. Now it is the new dimension to regulation - both in the content and role of the regulatory institutions - that must accompany the revolutionary challenge expected of power systems around the world in the next few decades to contribute to the transition to a sustainable energy model. Power systems will have to be decarbonised, neighbouring electricity markets will merge or coordinate to cover larger geographical areas, large amounts of intermittent renewable generation will be deployed everywhere, information and communication technologies will be integrated at all levels in power systems facilitating demand response and advanced control schemes, new business models will appear and universal access to electricity supply will be (hopefully) 
finally achieved" (Pérez-Arriaga, 2013). So current energy policy issues appear are the electricity market and the existent regulatory model in Europe ready to meet the challenges of a sustainable energy model in the future, what kind of measures are appropriate for the functioning of electricity markets and what actually is the role of regulation and regulatory institutions during this process? From this perspective, the research is focused on two parts: 1) clarification of the regulatory model of governance for electricity services and its challenges in the EU in the $21^{\text {st }}$ century, including the concept of services of general interest, as a core of the regulatory model in the EU, and 2) the effect of its approach, particularly in the energy services at the national level. The paper relates to the EU regulation of the electricity industry and discusses the most prominent opinions regarding regulatory design. It contains a regional aspect of this approach, based on the Bulgarian experience. The best way to introduce regulatory mechanisms and their design nowadays is to briefly review the theory of regulation and some basic terms that can be found in the literature. These are "regulation", "regulatory state" and "regulatory authorities".

\section{Theories of Regulation. The Terms "Regulation", "Regulatory State" and "Regulatory Authorities"}

According to the most prominent findings, the development of regulatory governance in the EU went through several theoretical explanations, known in the literature as normative and positive regulation theory. The distinction between these is crucially important for understanding the present and future role of the EU as a regulatory regime. Normative regulation theory appeared in the middle of the last century, when most of the scientists from different areas considered market failures as a basis for the emergence of so-called normative or legal regulation. This theory refers to different types of market failures - failure of competition; negative externalities; information failures; insufficient provision of public goods and services, such as national defense; and the existence of "incomplete markets", that need to be repaired. From the thirties, under the influence of the great depression, more and more economists were in favour of public enterprises. They considered that public intervention was the most appropriate way to meet the challenges of the power sector in this period. This sector exhibited the characteristics of natural monopolies hence public ownership was justified by the need to protect consumers from exploitation by private monopolies by imposing political power - some sort of legislation in order to meet the needs of society. However, the continuing experience demonstrated that public provision does not provide the overall effect for its implementation, mainly because of higher political influence over public enterprise. Therefore, as a counterpoint to normative theory a positive theory of regulation, which emerged in the 1970s, considers that regulation should not be based on increasing economic efficiency by correcting market failures, but by effectively redistributing wealth in society. According to Stigler, private markets are incomplete whenever they fail to provide goods or services even though the cost of providing them is less than what individuals are willing to pay. Thus, private markets have often failed to provide 
public interest, and governments have undertaken a number of programs motivated by this particular market failure.

Gary Becker (1983) developed the theory of economic (positive) regulation by presenting the concept of "inert loss" - a measure of the inefficiency of redistribution relating to the difference between the winners' profits and the loss of those who were defeated by the regulation. Becker establishes an interesting link between economic and regulatory theory of regulation, arguing that regulation is necessary in terms of efficiency, since neither the winners nor the losers, according to the concept of inert loss, are irrational. That is why both positive and regulatory theories of regulation should be regarded as complementary rather than mutually exclusive theories. At the same time, while presenting certain critical insights, neither positive nor normative theories can explain the complex dynamics of the regulatory process - the reason why regulatory bodies are developing and working. This explanation is suggested by the institutional regulation theory.

Institutional regulation theory addresses the issue of the role of institutions in the process of controlling private operators in the production and provision of services to society. The majority of the work of the institutional theory of regulation is devoted to exploring "the political and bureaucratic networks through which public policy goals are translated". The main component of the theory concerns the study of the delegation of power to "regulators". Analysts of institutional theory support the assumption that regulators could only be monitored through a combination of effective control tools such as "full executive power; stringent procedural requirements; professional standards; public participation and judicial control. When such a complex system functions properly, no authority will be able to control the regulatory agencies independently and so surely the agencies will be placed under public control" (Moe, 1987). Some of the theoreticians working in the field of regulation in Europe have criticized the "institutional asymmetry" between positive and negative rules-an asymmetry which they believe a supranational social policy should correct. Their contention is that while the rules of negative integration, being primary (i.e., treaty-based) European law, are directly enforceable by the European Commission and Courts, policies promoting social protection and cohesion - positive integration - usually require intergovernmental agreement (in some cases unanimous agreement) and are therefore designed and implemented with much greater difficulty. There is indeed an asymmetry between primary and secondary rules but it is far from clear how or even whether, it should be corrected. The basic reason for this asymmetry is that heavily regulated national markets could not have been integrated without primary rules restricting the interventionist tendencies of national governments, and the protectionist temptations of both publicly-owned and private firms. Since the method adopted by the founding treaty makes the integration of national markets the starting point of a long march toward "ever closer union", it follows that negative integration is a constituent, rather than a contingent, element of the grand strategy of the fathers of communitarian Europe. That is why in our opinion positive and normative theories should be viewed as complementary rather than mutually exclusive. For this reason it is necessary to underline the main characteristics of regulatory theory and its basic terms. 


\section{The Terms "Regulation", "Regulatory State" and "Regulatory Authorities"}

\section{A) The term "Regulation"}

The term regulation appeared in literature and in practice during the 1990s, when "the European Union and the Member States decided to gradually open the energy markets to competition" (Tsangaris, 2017). In the context of government and public services, regulation means establishing rules to control, but not to prohibit, an activity. Regulation can therefore be viewed as a compromise between prohibition (or more precisely command and control) and no control at all. Consequently, it is an expression of the exercise of authority through which the regulator (such as a government or the management of any given organisation) attempts to impose guidelines under the conviction that they will lead to a better result. In other words, it is a series of principles or rules (with or without the authority of law) used to control, direct or manage an activity, organisation or system. From a legal perspective, regulation can be defined as the rules based on and written in order to implement a specific piece of legislation. It is a form of secondary legislation issued by a government minister or a regulatory body under the authority of primary legislation, whose effective application it is meant to secure (Pérez-Arriaga, 2013). Moreover, regulation should aim to steer an industry's performance towards improving "general welfare", i.e. the collective benefit gained by consumers and operators. An industry's performance can be measured in terms of consumer surplus, service availability, profitability and affordability, range of services offered, quality and degree of innovation. This means that the "instruments of quality regulation require reliable measures of the corresponding dimensions of service quality. What is being measured is obviously a quality indicator. The measured quality indicators describe the actual performance of the regulated company. This information is in itself sufficient to make the simplest instrument - data publication - effective" (Fumagali, 2017). Monopoly regulation "is justified by the need to prevent a monopolistic provider from overcharging consumers or delivering a service of unacceptable quality, given the loss of economic efficiency this would entail for society as a whole. So, regulation seeks to protect consumers from the market power that may enable monopolies and oligopolies to set unjustifiably high prices or lower the quality of their goods or services. Regulations limit the prices that companies can establish and set quality and service continuity standards as well as rules about service coverage. Regulators also participate in investment planning in a number of ways: the State may plan investment directly, for instance, or subject companies' plans to administrative authorization" (Pérez-Arriaga, 2013).

Indeed, according to the literature, there are three basic meanings of the regulation.

- First, in the narrowest sense, the regulation means formulating a system of autonomous public bodies or other mechanisms for monitoring, investigation and enforcement of these rules. According to Selznick (1985) regulation is a constant and focused control of a public entity on activities that are considered important for the community. Creation of au- 
tonomous regulatory bodies came as a result of reform. This is the closest meaning of the concept.

- Second, the term regulation can be defined more broadly - as any type of state intervention in the economy or the private sector to lead them to achieve certain public purposes. This understanding goes beyond the development of rules and includes issues such as taxes, subsidies and public ownership. In this sense, regulation is one of the most comprehensive concepts in public governance.

- Third, at the most aggregate level, regulation means any social control, including control mechanisms or actions of any kind. In contemporary research approaches regulation is associated with an understanding of the development of rules and standards - monitoring and evaluating, as well as the possibility of imposing sanctions and incentives. From this perspective, the regulation as a governance approach uses independent bodies to implement the above three. They are considered as an instrument of regulatory policy and the reason for their occurrence is the need to protect the public interest.

A definition of the regulation covering all the essential features of it was proposed in 1985 by Philippe Selznik. For the regulation, the American sociologist writes "a sustained and focused control exercised by a public agency, based on a legislative act, on activities that are generally considered desirable by the society" (Selznik, 1985). However, we need to keep in mind that the regulatory model of governance is not static. It evolves and changes according to the world dynamics and the changing needs of society.

\section{B) The term "Regulatory State"}

The term Regulatory State is much more narrowly defined than the regulation - contribute to the efficiency of the economy, to protect competition, consumers and citizens. The Regulatory state puts particular emphasis on its regulation at the expense of other instruments in the policy process. It is a State which sets rules rather than a state that collects taxes and spending budgets. Regulation is an instrument of the regulatory state whose aim is to control the release of goods and services on the market with an emphasis on consumer rights. This means that the regulation consists of at least three basic elements. These are - "the design of rules for steering agents' behaviour towards the objectives defined by the regulator, the structure of the power industry, when market mechanisms are adopted, an appropriate business structure is generally needed and the supervision of agents' behavior" (Pérez-Arria$\mathrm{ga}, 2013)$. The last one is the main job of the regulatory authorities.

\section{C) The term regulators or regulatory authorities}

The terms regulators or regulatory authorities are a product of the emergence of the model of the regulatory state. Regulators are specific bodies whose main tasks are: "to control the power and the influence of market players, to ensure fair competition, to protect consumers and citizens and to guide and implement regulation policy" (Andreeva, 2016). Usually regulatory authorities appear as a result of EU legislation. Mainly, there are three types of regulatory authorities - independent ministries agencies, independent regulatory commissions and independent advisory agencies. 
- Ministries and Ministerial Agencies

The ministry "concerned is the part of the executive branch of government specifically responsible for the considered industry. Some countries have created agencies (under different denominations) associated with the respective ministry. These institutions operate with an independent budget, are independently managed and may be subject to separate legislation (because they are not subject to the rules governing civil service, for instance), although they are in one way or another ultimately subordinate to the ministry. Even so, ministerial agencies operate with relative independence in many countries.

- Independent Regulatory Commissions

Independent regulatory commissions (often called independent regulatory agencies, authorities, bodies, commissions or committees) are public bodies entrusted with regulating specific aspects of a given industry, a characteristic that distinguishes them from mere advisory bodies. Regulatory commissions share regulatory powers with other public institutions, the ministry concerned in particular, and are fairly free of short - term political influence. Their duties often include regulating grid access and determining grid and end-user tariffs. Regulatory commissions may have judicial or quasi-judicial powers, such as establishing fines and penalties for noncompliance or acting as arbiters in disputes between industry players. Some commissions are also explicitly mandated to protect end users and regulate entry and exit through licences, where the rights and obligations of the licensees are specified. Some commissions also intervene in the processes of authorization of mergers and acquisitions of companies in the particular sector. Independent commissions may be characterised by the degree of political independence and the extent of their authority. In addition to being vested with independence and specific powers, independent regulatory commissions share regulatory responsibilities with the competent ministry. Theoretically at least, decision making (the establishment of a general framework and rules) is generally left to the ministry, while the regulatory commission's responsibility is to enforce the ministry's rules and sometimes to develop them in detail. The boundary line between policy and regulation is blurred, however, and some overlapping is inevitable.

- Independent advisory agencies

Some countries have created independent advisory agencies. These institutions do not answer to the ministry, which cannot even revoke the appointment of agency members. While the terms of reference of their advisory mandate are broad, they are vested with no decision-making power in regulatory matters. They are often responsible for monitoring areas such as grid access and dispute settlement" (Pérez-Arriaga, 2013).

These three types of institution each have different powers. The most powerful are the independent regulatory commissions and the ministerial agencies; other institutions such as independent advisory agencies may also play a potentially significant role, albeit without legally regulatory powers. Furthermore, at European level the type of institution varied across Member States. For exam- 
ple, in the Bulgarian energy sector the regulatory authority is the State Energy and Water Regulatory Commission (SEWRC).

At the same time, the implementation of the regulatory model varies in the different countries because of their specifics. However, at the current stage, at European level, the regulatory model refers to set a general rules and its implementation in order to protect consumer rights in the context of liberalization. From this point of view, the concept of services of general interest - access to goods and services under certain quantity, quality and price, plays significant role in understanding the contemporary European model of supplying energy services.

\section{The Concept of Services of General Interest (SGI) as a Core of the Regulatory State in the Europe}

\section{Definition of the concept-general overview}

It is often argued that the establishment of a concept of services of general interest in the European Union is difficult because the concepts vary in the different Member States. The problem of its definition and institutionalization is even more acute, since the efforts to establishment the internal market and the enlargement of Europe, involves the integration of new countries, which also have their own definitions of public services. Among the differences in approaches, however, there are common trends that help to build the concept of services of general interest at Community level.

From a historical point of view the development of the concept of services of general interest can be divided into two phases. The first phase covers the period from the Treaty of Rome (1957) to the early 1980s. During this period services of general interest were not defined (historically, the term "services of general interest" could not be found even in the Treaty of Rome) and remain outside the scope of the EU institutions. The reason for this is that European Community is characterized by no competence, resulting from European legislation, and no common term. In practice, the regulation of services of general interest in this first phase remains the responsibility of the Member States, whose main task is to establish progressive regulation and intervention policies for the sake of competitive markets on a supranational level.

The second phase appeared in the early 1980s, when the processes of privatization and deregulation had begun to dominate. If there is no suitable legislation or the existing one is not being properly applied, this would limit open access to goods and services for European citizens. Furthermore, the lack of rules leads to collusion among market participants, which again has a negative impact on prices, quality and availability of services. This requires the European Commission to take measures to define the term and the concept of services of general interest, putting emphasis on the importance of consumer rights in the context of liberalization - access to goods and services under certain quantity, quality and price on the one hand and, on the other hand, the smooth functioning of the market.

Generally the concept of "services of general interest" in the EU is associated with two main theoretical concepts - the organizational concept and the 
functional concept. The first one presents services of general interest "as services delivered by public or by private enterprises, and the second one focuses on ensuring minimum human needs rather than focusing on the type of enterprise - public or private" (Boben, 2014). This is why in the 90s the European Commission decided to clarify the concept of services of general interest. The Commission accepted that "SGI are services that the public authorities classify as such by general interest and are subject to specific public obligation" (European Commission, 2003). Thus the focus is not on ownership, but on the rights of consumers in term of liberalization.

Indeed, at European level the term 'services of general interest' is derived from the more narrow term - services of general economic interest. The latter is used in Articles 16 and 86(2) of the Treaty. The services of general economic interest in particular cover certain services provided by the big network industries such as transport, postal services, energy and communications. The term also extends to any other economic activity subject to public service obligations. Put another way - services of general economic interest are "economic activities that public authorities identify as being of particular importance to citizens and that would not be supplied (or would be supplied under different conditions) if there was no public intervention" (European Commission). Examples are: the energy sector, transport networks, and postal services. Unlike them, the term "services of general interest" is a general category. According to European documents SGI includes all services, such as education or health related, regardless of whether they are economic or non-economic. That is why we should assume that SGI cover both: the private and the non-private sectors with a greater focus on consumer rights. Furthermore, the terms "service of general interest" and "service of general economic interest" must not be confused with the term "public service". The term "public services" is less precise. It can have different meanings and can therefore lead to confusion. This term sometimes refers to the fact that a service is offered to the general public. It is sometimes highlighted that a service has been assigned to a specific role in the public interest and it sometimes refers to the ownership or status of the entity providing the service. However, among the differences in the approaches, there are some common elements that help to establish the concept of services of general interest in the European Union. These elements identify the Community values and goals and have been transposed into obligations in the respective legislations of the Member States. They include an understanding of universal service and its features - continuity, quality of service, affordability and consumer protection, as well as some additional specifics, such as - protection and security, security of supply, open access and interconnectivity, as a basis for supplying services of general economic interest in the EU.

\section{Understanding the Concept of Universal Services as a Basis for Supplying Services of General Interest in the EU}

The Community understanding of the concept of universal services "refers to a set of general interest requirements ensuring that certain services are made available at a specified quality to all consumers and users throughout the territory of a Member State, independently of geographical location, and, in the 
light of specific national conditions, at an affordable price" (Green paper, 2003). It has been developed specifically for these sectors of the economy, including the traditional state "natural" monopolies, such as postal services, railroads and the energy sector. In these sectors, especially the energy sector, the various enterprises carry out certain activities in competition and certain public service missions. "They are obliged by law, by their statutes, or by some other institutional specifically of their carrier to provide such general-interest functions as private-economy enterprises in competition would tend to shrink away from them because of their low return on investment or unprofitable character. Enterprise structures, organizational forms and regulations for the provision of public missions nowadays appear to be changing in the classical public enterprise sectors" (Cox, 1999). This is valid for many sectors and services and therefore leads to some specific obligation via different Member States. At the same time, the concept of universal service is a dynamic. It ensures that general interest requirements can take account of political, social, economic and technological developments and it allows these requirements, where necessary, to be regularly adjusted to the citizens' evolving needs. According to the European Commission it is also a flexible concept that is fully compatible with the principle of subsidiarity. Where the basic principles of universal service are defined at Community level, the implementation of these principles can be left to the Member States, thus allowing different traditions and specific national or regional circumstances to be taken into account. Furthermore, the concept of universal service can apply to different market structures and can therefore be used to regulate services in different stages of liberalization and market opening.

The main principles of this concept are - continuity of supply, quality of service, affordability and consumer protection.

A) Continuity of supply is a fundamental principle of the European understanding of the universality of services of general economic interest. Continuity means that some services that are delivered to society are of such importance that their continuous delivery is an objectively necessary condition for the citizens and therefore becomes an obligation of the respective provider. This principle is valid especially to services of general economic interest, such as energy services, and therefore it is necessary to impose a legal continuity requirement on the operator provider.

The concept of continuity of supply is an important element of the overall European policy on services of general interest. The reason for this is that continuity of supply guarantees a reduction in disparities, ultimately resulting in economic and social cohesion - an essential element of the European integration policy of the EU. Moreover, continuity is one of the main arguments against the market principle for the provision of services of general interest. It is also a basis of the new model of governance service in the 21st century in the EU.

B) Quality of service is another fundamental principle in the delivery services of general interest in the EU and at a national level, and therefore it is important to understand the new model of their governance.

The transfer provision of general-interest services from the State supplying the private economy in the 1980s determines the need to take measures to 
protect the quality of the services. The main argument at European level is that the Community did not rely on market forces alone to maintain and develop the quality of services, especially for those classified as network industries. In order to maintain the quality of the electricity network, for example, the respective private operator has to set a percentage of investment costs for its maintenance. However, this cannot be achieved in some cases, for various reasons. That is why the definition, monitoring and implementation of quality requirements by public authorities have become key elements in the regulation of services of general interest nowadays.

C) Affordability is a principle developed within the framework of EU regulatory policy of telecommunications, subsequently applied to other public utilities. It requires a service of general economic interest to be offered at an affordable price in order to be accessible for everybody. The European Community considers that the application of the principle of affordability helps to achieve economic and social cohesion within the Member States. Furthermore, this principle is one of the common values enshrined in Protocol No. 26 on services of general economic interest (annexed to the Treaty) in which the Union and the Member States, in accordance with their powers, must take full account of when implementing all related policies.

D) Consumer protection is a principle also developed especially for the services of general economic interest such as energy services (electricity and gas), water services, postal services, telecommunications and other, because of the particular economic and social importance. In this regard, according to the European documents consumer protection includes good quality of service, high levels of health protection and physical safety of services, transparency (e.g. on tariffs, contracts, choice and financing of providers), choice of service, choice of supplier, effective competition between suppliers, existence of regulatory bodies, availability of redress mechanisms, representation and active participation of consumers and users in the definition and evaluation of services, and choice of forms of payment. This means that in terms of a liberalized market, public services have been identified as one of the policy areas where action is needed to ensure a common high level of consumer protection.

\section{Additional Elements in Understanding the Concept of Services of General Economic Interest in the EU}

During the last two decades of the 20th century, the European understanding of universal service developed into a major and indispensable pillar of the Community's policy on services of general economic interest. This has allowed public interest requirements to be addressed in various areas such as economic efficiency, technological progress, environmental protection, transparency and accountability, consumer rights and others (Green paper, 2003). The concept has also contributed to reducing the levels of disparity in living conditions and opportunities in the Member States.

The European understanding of the universality of services of general interest allows the essential elements of the concept to be complemented by other specific obligations depending on the characteristics of the sector concerned - 
by the type and specificity of the service. They have been transposed into obligations in the respective legislations and aim to ensure different objectives of public interest. Such obligations include: ensuring safety and security, security of supply, and access to networks.

A) Safety and Security requirement relates to "a common set of objectives, concerning almost all Member States" (Green paper, 2003). Normally, national security and state border protection have traditionally been carried out with the help of the State, but in a world that is rapidly and dramatically changing, European citizens need to be protected. That is why the Commission is increasing the level of security as well as adopting a more European approach in certain fields such as transport and energy. The reasons for this new approach are widespread and various. For example, problems usually exceed national frontiers, international conventions and rules do not usually have binding force, and Member States are sometimes confronted with the limitations imposed by Community rule.

B) Security of supply is one of the most important elements of the European concept of supplying public services.

The development of the internal market has generated a considerable increase in the level of security of supply of products and services, to the extent that the markets concerned are functioning competitively. However, in some cases concerning services of general interest, such as energy services, public intervention may be necessary to improve the security of supply, in particular in order to address the risk of long-term underinvestment in infrastructure and to guarantee the availability of sufficient capacity. It should be noted, however, "this is not a public supply of services but State regulation of certain areas for security of supply" (Andreeva, 2016). In the energy sector, for example, the issue of supply security has been the subject of broad public debate at Community level in order to ensure the uninterrupted physical availability of energy products on the market, at a price which is affordable for consumers and users, while taking into account both environmental concerns and sustainable development.

C) Access to networks - Where there is effective competition, market mechanisms may ensure the provision of affordable services of an adequate quality, thus greatly reducing the need for regulatory intervention. Where services of general economic interest are provided on the basis of networks with universal coverage, the incumbent undertaking enjoys a substantial competitive advantage, mainly due to substantial sunk costs involved in establishing and maintaining alternative networks. In cases where competitors can only operate as service providers, access to the incumbent network is indispensable for market entry. However, even in sectors where competitors do have the right to deploy their own network infrastructure network access may be necessary for competitors to be able to compete with the incumbent on downstream markets. If third party access to existing networks at fair and non-discriminatory conditions was not possible, de facto monopolies or at least the incentive for the incumbent to discriminate in the access terms, thus distorting competition downstream, would be maintained. Therefore, in order to meet competition policy and internal market objectives, thereby offering customers more 
choice, higher quality and lower prices, sector-specific Community legislation for the sectors liberalized at Community level harmonizes and regulates the access to network infrastructures (Green paper, 2003).

The European model for governance services of general interest in this case refers to the development of different regulatory strategies depending on the type of network industry and the different stages of the liberalization process. At the same time the implementation of this model varies amongst different Member States. It depends on the stage of liberalization, the political power influenced and the region. In other words, "models can be classified on the grounds of which activities have been "unbundled" and which deregulated. For example, there is the vertically integrated monopoly, in which none of the activities are separated or deregulated. This is what is known as the traditional model. The other extreme is the full retail competition model. In this model, activities are vertically disaggregated and generation, supply and trading or transacting are performed competitively" (Pérez-Arriaga, 2013). The early power sector developments at the end of the nineteenth century and beginning of the twentieth century were mostly driven by private initiative and competition. However, in most countries this was replaced by strong governmental intervention in the form of public ownership or treatment of the electricity companies as regulated monopolies. During most of the past century and until the 1990s, the electricity industry regulation worldwide was based on a quasi-standard regulatory approach involving heavy State planning and intervention, with the State being the sole regulator. Under this traditional model, prices are fixed to cover the costs incurred by electric utilities, while investments either require regulator authorisation or are State planned. This approach precludes any electricity market per se and transactions are conducted via the rules laid down by the regulator. Consequently, the vertical and horizontal structure prevailing in the industry is of scant importance, which often has led to the existence of a single utility, a vertically integrated monopoly with a territorial franchise. Today, this traditional regulatory paradigm has changed in many countries. The main component of this change is the creation of electricity markets that provide the platform for trading and establishing prices. The first step in creating such markets is the elimination of the limitations to competition that characterises the traditional scenario. While calling for broad knowledge and technical analysis, all it involves is drafting and approving suitable legislation for the industry (PérezArriaga, 2013). We are going to discuss this issue in the next part of the paper, based on the Bulgarian experience.

\section{The Influence of the European Regulatory State particularly in the Bulgarian Electricity Market}

Electricity is an example of "a commodity with spatially separated but connected markets. A producer at one location can sell to local customers, or can pay the transmission grid to have the power transmitted to customers at another location. Like other commodities with spatially distributed markets and transpor- 
tation costs, the result is different prices in different locations" (Gabriel, 2013). This is the reason why European energy policy is based on the principle that an independent regulated and competitive energy market is the most effective and efficient way to achieve a common energy market and long-term competitiveness of the economy.

The construction of the Bulgarian electricity market in accordance with competition rules and protecting consumer rights (as required by the $\mathrm{EU}$ ) began in the 90s starting with three main packages of EU legislation as part of the European regulatory model. These are: 1. First liberalization package of the EU since 1996; 2. Second liberalization package of the EU since 2003 and 3.Third liberalization package of the EU since 2009. All of the packages required common rules for all member states in order to achieve the European goal - a common electricity market. They prescribed the electricity market to be fully open to competition by 2007 by creation of effective rules, equal treatment and transparency of all participants in the energy markets, open access to energy infrastructure and the existence of independent regulatory authorities. The main reason for this was the ineffective operation of the electricity markets, mainly the fact that many European countries kept following the model of vertically integrated undertaking. The vertically integrated energy companies refer to companies which perform at least two of the following: production, transmission, distribution and/or storage in electricity, when one entity can control the other. From this point of view it is appropriate to answer the question as to what has happened in Bulgaria in the Electricity market field, according to the European legislation.

In Bulgaria the original form of operation of the electricity market was established based precisely on the "vertically integrated undertaking" model. In this case the Bulgarian company - National Electricity Company - was the only public provider of electricity and the owner of the transmission energy network up until 2014. This meant that there was no free access to the transmission network for third parties and the company could continue cross-subsidization by purchasing cheap and expensive electricity, and finally selling it at union price. This model of the Bulgarian market was valid until 2014 when the transmission network was transferred to the state-owned company - Bulgarian Energy Holding.

In the present case, the electricity market is defined as a set of legal, technical and economic norms for the relationships between the parties involved and the means to support their activities in the purchase and sale of electricity and its derivatives. In a broader sense, the electricity market also includes the stage of development of the main tools (trade in design, construction, and operation of energy facilities), as well as trade of assets of energy companies. These are markets for long-term goals, unlike markets with short-term goals where the main production assets are such as the trading of electricity and its derivatives in invariable terms of the means of production, transmission and distribution.

The energy system today is highly dependent on the chain of systems or activities required to ensure the supply of energy known as the energy supply system. The supply system "is made up of the supply sector, the energy transforming sector and the energy consuming sector. The supply involves indigenous production, imports or exports of fuel and changes in stock levels (either stock 
pileup or stock draw down). Transformation converts different forms of primary energies to secondary energies for ease of use by consumers. Transformation processes normally involve a significant amount of losses. Transportation and transmission of energy also involve losses. The final users utilise various forms of energies to meet the needs of cooling, heating, lighting, motive power, etc. The relative importance of the above segments varies from one country to another and even from one fuel to another depending, to a large extent, on the availability of resources in a particular country. For a resource-rich country, the supply segment is evidently well developed while for a resource-poor country the transformation and final use segments tend to be more developed" (Bhattacharyya, 2011). Moreover, "many Electric systems (EES) have been practically deployed for various applications in the power grid. They can be used as commodity storage for storing energy during off-peak periods for the use during peak periods for arbitraging electricity price. Such applications may decrease peak load demand (i.e., peak shaving), or make the load demand uniform over time (i.e., load leveling). The purpose of such applications is mainly to reduce the maximum capacity requirement in generation, transmission, and distribution systems, and hence reduce the cost of power generation" (Younghyun, 2014). Current energy systems are the result of complex country dependent, multisector developments. By considering energy supply and demand across all sectors simultaneously, systems analysis applies systems principles to aid decision-makers in problems of identifying, quantifying, and controlling a system. Many people "discuss solutions to the energy problem, but often they completely underestimate the order of magnitude of the problem and solutions are offered that nicely work at small scale but not at global scale" (Durem, 2017). The relationship "between the structure and the behaviour of the interacting units forming a network, namely, a complex system, is one of the most studied topics in recent years" (Rubido, 2016). Building an energy systems model requires a number of key components, namely a model generator, a solver, interfaces for handling data and results and a detailed database. Energy system models also require key exogenous inputs, comprising the demand component (energy service demands), the supply component (resource potential and costs) and the policy component (scenarios) (Giannakidis, 2015).

At the current stage, the electricity market in Bulgaria is based on two parallel operating segments. These are: the market of regulated prices and the market of freely negotiated prices.

The market of regulatory prices is characterized by the prices, approved by the State Energy and Water Regulatory Commission (The Bulgarian regulator); the parties of the transactions are determined by legislation; relations are regulated on the basis of measured quantities of energy; participants do not balance; the price of access and transfer is paid to the existing supplier.

The market of freely negotiated prices is characterized by regulated part and unregulated part. The regulated part of the market is organized through contracts with the National Electricity Company (NEK EAD) at prices regulated by the SWERC. The unregulated part works through freely negotiated prices between participants. 
The final prices of electricity for the regulated market are formed in the chain production - transmission - distribution - supplying and are determined by the Bulgarian Regulatory Commission. Generation/production, transmission, distribution and supplying are key elements of the power system in Bulgaria.

The generation of electricity in Bulgaria comes from four types of producers - from the Bulgarian nuclear power plant - NPP Kozloduy, from conventional power plants such as TPP Maritza East 2, from plants using renewable energy sources (RES) and from plants with a combined method of producing heat and electricity power.

Electricity transmission is performed by the power grid operator, licensed for transmission and certified. The Bulgarian Electricity System Operator EAD ("ESO") was established on 4 April 2007 as a subsidiary of the National Electricity Company ("NEK"). On 4 February 2014, the unbundling of ESO from NEK went through its last stage in line with the Third Liberalization Package. This has been the final step needed to reach compliance with Directive 2009/72/ $\mathrm{EC}$ and the national legislative provisions. ESO is responsible for the common operational planning, coordination and control of the Bulgarian power system and its parallel synchronous operation with neighbouring systems. Its purviews also include transmission grid operation, maintenance and reliable functioning, auxiliary network servicing, as well as maintenance and repair services in the energy sector. It also manages the power transit through the national grid and runs the electricity market. In performing a parallel synchronous operation with ENTSO-E, ESO, being a key partner in the Balkan region, it constantly strives to achieve higher transmission efficiency and asset management performance by introducing and using the newest methods of planning, maintenance and monitoring. The company has deployed an asset management system (SAP/R3), Supervisory Control and Data Acquisition System (SCADA), and Geographic Information System (GIS).

Electricity System Operator" EAD is certified as an Independent Transmission Operator (ITO).

Electricity distribution and operation of distribution networks in Bulgaria are carried out by operators of electricity grids. These are four foreign companies - "Energo-Pro Network" AD (Northeastern Bulgaria), "CEZ Distribution Bulgaria"(Western Bulgaria) "EVN Bulgaria Electricity" AD (Southeast Bulgaria) and "Electricity Distribution Company Golden Sands" (Golden Sands). All have licenses for the distribution of electricity, granted by the national regulator.

The activities on the public supply of electricity in Bulgaria are performed by "CEZ Electro Bulgaria" for Western Bulgaria, "Energo-Pro Sales" for Northeastern Bulgaria, "EVN Bulgaria Electricity" for Southeast Bulgaria and "Golden Sands" - providing public electricity supply within the resort Golden Sands.

Besides transactions at regulated electricity prices, producers are able to sell their production and through direct sales at freely negotiated prices. Transactions in this market segment are performed in the presence of additional production facilities which fall outside the specified purchase quotas. This is the so-called "Bilateral contracts with the balancing market". 
Figure 1

\section{Structure of the Bulgarian balancing market}

Sale

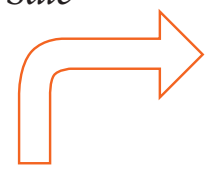

Production/

generation

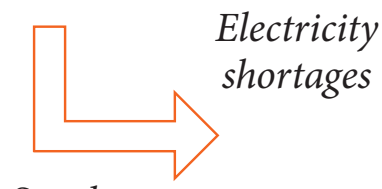

Surplus

energy

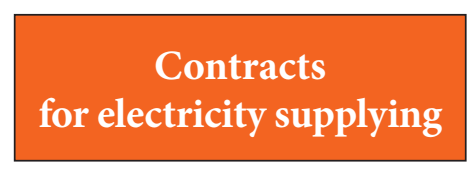

Purchase
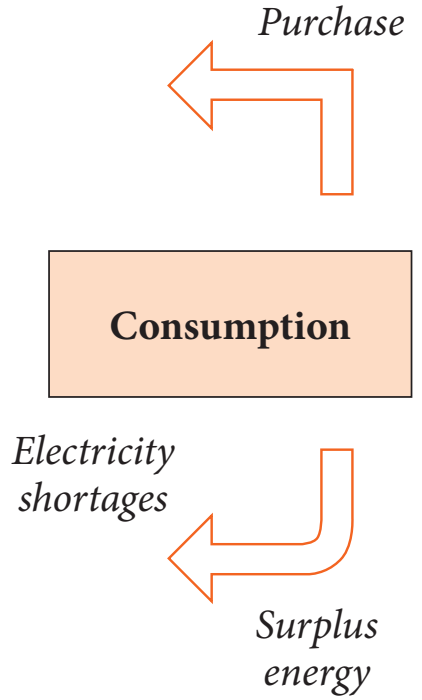

The basic principle in this market model is dispatching producers in accordance with the quantities of electricity. This model allows new players - "electricity traders". The aim has been for electricity traders to compete with electricity distribution companies, as they are given the right to supply electricity by free market prices. Those market players have been introduced by the new energy law since 2007. The idea has been for electricity trading to be separated from distribution. However, "the current distribution and use of electricity is largely an outdated legacy infrastructure which results in gigantic inefficiencies" (Brena, 2015). A recent trend to solve this situation "is the gradual incorporation of more flexible elements of the electricity market. Distributed generations contribute to the supply diversity as well as the competitiveness of the electric market. Electric power supplies and load users all seek to optimally allocate/ utilize the energy to maximize their benefits" (Xu, 2017). In fact, this model marked the beginning of liberalization of the Bulgarian electricity market by starting the Energy Stock Exchange/ Power Exchange.

The establishment of the Bulgarian stock market of electricity is a basic prerequisite for the liberalization of the energy market. Its aim is to create conditions for operating the electricity market in a competitive, transparent and non-discriminatory environment; to determine reference electricity prices according to supply and demand needs and to ensure optimum use of the transmission capacity of interconnections with neighboring countries. The Bulgarian stock exchange market is organized on a daily basis for a single hour. Transactions concluded on the stock market represent a strong commitment for electricity traders to supply electricity. Each transaction is linked to one day, one interval and one market area of delivering electricity.

Overall, compared to other member states, Bulgarian efforts to reform their electricity market started late and seem largely incomplete. The Bulgarian electricity 
market still presents a hybrid model. Part of the transactions for the sale of electricity is concluded at regulated prices approved by the Regulator, and the rest is traded on the liberalized market at freely negotiated prices. The share of the regulated segment of the electricity market is still in the range of $75 \%$ to $90 \%$. The small share of the free market in Bulgaria means that the competition can not properly perform its function of ensuring efficiency in this segment of the market. The design of the electricity market in Bulgaria is suboptimal, with its flaws. Despite the partial privatization of assets for production and distribution, the vertically integrated, fully state-owned company - Bulgarian Energy Holding "BEH" - retains the central role, together with its subsidiary company - National Electricity Company.

Electricity has become the most popular exchange commodity nowadays. Bulgaria, however, is one of the few countries in Europe that have no effective exchange energy market, although since 2007 (due to EU requirement) the electricity market in the country had to be liberalized. Practically, the Bulgarian Power Exchange even appears in 2016 after the test performance of the "Independent Bulgarian Energy Exchange" in 2015 (a separate company again within the framework of the Bulgarian Energy Holding). Such a model leads to ineffective operation of the market and a lack of confidence from market participants.

In the world of perfect competitive markets, "little regulatory effort is perhaps required. But when such ideal markets do not or cannot exist, regulations then aim at controlling the behaviour of the market agents to control the market failures and to produce competitive market-like results through the use of coercive power of the government or its agencies that restrict or constrain the decisions of the economic agents" (Bhattacharyya, 2011). The dilated reform of the Bulgarian electricity market largely depends on the role of the Bulgarian regulator. When, the institutional characteristics of the regulator - its adequacy, independence, autonomy, and its relationship with political power and the companies it regulates are compromised, this slows down reform, as in it ultimately turns the opening of the energy market to competition and protection of the general interest in an impossible process. In Bulgaria the issue of the independence of the regulatory authority is emblematic. Among the main criticisms of the Bulgarian Energy and Water Regulatory Commission is the lack of independence and governance capacity. The effectiveness of regulation in Bulgaria often is limited by government influence. In addition, a central place in the direction of quality and effective regulation of the energy services is also the question of the capacity of the regulator.

In order to avoid these shortcomings in the opening of the electricity market and, at the same time, to protect consumers' rights within the EU liberalized market we offer the following measures:

A) The establishment of an independent regulatory design. Removal from executive and corporate interests is a prerequisite for a more efficient regulatory process in Bulgaria. This would solve many problems related to the addiction of the regulator and the resulting ineffective regulatory decisions preventing the opening of competition into the Bulgarian electricity market. It is important for the regulator to conduct transparent procedures and to impose transparency on requirements in the decision-making process. 
B) The establishment of close cooperation of the Bulgarian regulator with the regulatory authorities of the Member States. The aim is to take and apply the best European practices. Such cooperation would allow the most efficient model to be chosen for the functioning of a future energy exchange in Bulgaria.

C) The establishment of a real Energy Stock Exchange. The operation of the energy exchange is established at freely negotiated prices, which is among the most important prerequisites for opening up the electricity market to competition. With a functioning energy exchange, competition will not only be in the pricing, but also in terms of delivery, the way the bills are paid, and the development of the energy services offered in addition by the suppliers. The meaning of a freely functioning energy exchange is that participants will be phased out of the regulated market and will negotiate the supplied electricity, price and quantity only on a market principle.

\section{Conclusion}

Based on the presented research, the following main findings can be drawn:

1) The European regulatory model for energy services is a relatively new approach which appeared in the last two decades of the 20th century and it is part of the wider debate about the liberalization of services of general interest in the European Union (EU). At Community level, in a liberalized market, rights of access to services are defined in different legislation (directives). From a theoretical point of view, the regulatory model of energy services in the EU refers to legal regulation, imposing rules on the Member States (public service obligation) to ensure the rights of European citizens - access to goods and services under certain quantity, quality and price. Thus regulated private enterprises appear and the approach of combining regulation with competition rules applies. The classical hierarchical model of public governance in supplying electricity services, based on government control, is replaced by a new model of governance - the regulatory state. The main characteristics of this model are the existence of national regulators and the European legal framework in order to protect consumer rights in terms of competition, i.e. liberalization of services in combination with applying reasonable regulation. Current energy policy issues appear, related to assuring a secure supply of energy, keeping energy costs low, environmental protection, and ensuring the appropriate role of the energy regulation institutions.

2) The theoreticians and political leaders from the public governance sphere in Europe must note the fact that the paradigm of supplying public services has changed from the classical provision to regulation in the general interest. The principle underlying this is the pressure which came from the emergence of the processes of privatization, liberalization and deregulation at the end of last century. The regulatory model is a result of this because the functional capacity of competition on the one hand, and the implementation of the public contract on the other, must be guaranteed. Moreover, in the European Union, the creation of the internal market has accelerated this model. 
3) Regarding the specifics of the European model we come to the conclusion that it is not generally valid. The regulatory model of governance services general interest depending on the type of service. At the moment, the new governance model has the strongest impact on public utilities, such as the energy sector. In those sectors, European legislation is the most developed, while having a serious impact at a national level. For other services, for example - social services such as health services, the Community influence is limited. Regulation is largely determined by the Member State concerned.

4) At a national level, the Regulatory model of supplying energy services leads to mixed results. The Bulgarian regulatory model does not fully correspond to the nature of the created European regulatory model. The Bulgarian energy market is still facing some problems relating to the transposition of European norms. At a national level the organization of the sector continues to keep the vertically integrated company model where the state-owned company Bulgarian Energy Holding retains the central role even in the operation of the electricity market. As a result, Bulgaria still does not have a real working liberalized market for energy services, which seriously hinders competition and the creation of a common internal European energy market, on one hand, but also undermines the interests of citizens, the main users of public services, on the other.

\section{REFERENCES}

1. Andreeva, L. (2016). Services of General Economic Interest. The Bulgarian Regulation of Electricity Market and Production from Renewable Energy. Sofia: University Press St. Kliment Ohridski, pp. 89-131.

2. Bhattacharyya, S. (2011). Energy Economics. Concepts, Issues, Markets and Governance. London: Springer; New York: Dordrecht Heidelberg, pp. 1-163.

3. Boben, P. (2016). Public Lecture of French Institute about Services of General Interest. Sofia, Bulgaria.

4. Bognetti, G. (2008). Liberalization and Privatization of Public Utilities: Origins of the Debate, Current Issues and Challenges for the Future. Annals of Public and Cooperative Economics, vol. 79, no 3/4, pp. 461-485.

5. Brena, R.F., Handlin, C.W. \& Angulo, P. (2015). A Smart Grid Electricity Market with Multiagents, Smart Appliances and Combinatorial Auctions. International Smart Cities Conference. Institute of Electrical and Electronics Engineers Inc., Scopus.

6. Cox, H. (1999). The Provision of Public Services by Regulation in the General Interests or by Public Ownership? A Consideration of Recent Developments in the Public Economy under Aspects of Institutional Competition. Annals of Public and Cooperative Economics, vol. 70, no 2, pp. 161-177.

7. Durem, M. (2017). Understanding the Bigger Energy Picture. Springer Briefs in Energy, pp. 5-45.

8. European Commission (2003). Green Paper on Services of General Interests. Brussels: Commission of the European Communities, pp. 1-63. 
9. Fumagali, E., Schiavo, L.Lo \& Delestre, F. (2017). Service Quality Regulation in Electricity Distribution and Retail. Springer, pp. 8-21.

10. Gabriel, S., Conejo, A., Fuller, D., Hobbs, B. \& Ruiz, C. (2013). Complementarity modeling of energy markets. Springer, pp. 477-514.

11. Giannakidis, G., Labriet, M., Gallachóir, B. \& Tosato, G. (2015). Informing Energy and Climate Policies Using Energy Systems Models. Springer, pp. 1-25.

12. Hoeglinger, D. (2016). Politicizing European Integration. Struggling with Awakening Giant. Springer, pp. 100-125.

13. Majone, G. (2007). The Rise of the Regulatory State in Europe. West European Politics Journal, vol. 17, no 3: The State in Western Europe Retreat or Redefinition? pp. 77-101.

14. Majone, G. (2010). The Transformations of the Regulatory State. Osservatorio sull'Analisi d'Impatto della Regolazione. Available at: http://citeseerx.ist.psu.edu/viewdoc/download? doi=10.1.1.688.6697\&rep=rep1\&type=pdf (accessed: 31 October, 2017).

15. Moe, T. (1987). Interests, Institutions and Positive Theory: The Politics of the NCRB. Studies in American Political Development, no 2, pp. 236-99.

16. Rubido, N. (2016). Energy Transmission and Synchronization in Complex Networks. Springer, pp. 1-13.

17. Selznick, P. (1985). Focusing Organizational Research on Regulation. In: R.Noll (ed.) Regulatory Policy and the Social Sciences. Berkeley and Los Angeles: The University of California Press, pp. 203-351.

18. Tsangaris, P. (2017). Capacity Withdrawals in the Electricity Wholesale Market: Between Competition Law and Regulation. Springer, pp. 5-35.

19. Pérez-Arriaga, I.J. (2013). Regulation of the Power Sector. Springer. pp. 125-647.

20. Xu, Y., Sun, H. \& Liu, H. (2017). Distributed solution to DC optimal power flow with congestion management. International Journal of Electrical Power and Energy Systems, pp. 73-82.

21. Younghyun, K. (2014). Design and Management of Energy - Efficient Hybrid Electrical Energy Storage Systems. Springer, pp. 11-27.

\section{DOCUMENTS OF THE EU}

1. Directive 96/92/EU of the European Parliament and of the Council concerning common rules for the internal market in electricity.

2. Directive 98/30/EC of the European Parliament and of the Council concerning common rules for the internal market in natural gas.

3. Directive 2003/54/EC of the European Parliament and of the Council of 26 June 2003 concerning common rules for the internal market in electricity and repealing Directive 96/92/ EC - Statements made with regard to decommissioning and waste management activities.

4. Directive 2003/55/EC of the European Parliament and of the Council of 26 June 2003 concerning common rules for the internal market in natural gas and repealing Directive 98/30/EC.

5. Directive 2009/72/EC of the European Parliament and of the Council of 13 July 2009 concerning common rules for the internal market in electricity and repealing Directive 2003/54/EC.

6. Directive 2009/73/EC of the European Parliament and of the Council of 13 July 2009 concerning common rules for the internal market in natural gas and repealing Directive 2003/55/EC. 